\title{
Simple standard equation for daily step count in Japanese patients with chronic obstructive pulmonary disease
}

This article was published in the following Dove Press journal: International Journal of Chronic Obstructive Pulmonary Disease

\author{
Masanori Nakanishi ${ }^{1}$ \\ Yoshiaki Minakata $\mathbb{D D}^{2}$ \\ Rie Tanaka ${ }^{3}$ \\ Hisatoshi Sugiura ${ }^{3}$ \\ Hikaru Kuroda ${ }^{4}$ \\ Makoto Yoshida ${ }^{5}$ \\ Nobuyuki Yamamoto' \\ 'Third Department of Internal Medicine, \\ Wakayama Medical University, \\ Wakayama, Japan; ${ }^{2}$ Department of \\ Respiratory Medicine, National Hospital \\ Organization Wakayama Hospital, \\ Wakayama, Japan; ${ }^{3}$ Department of \\ Respiratory Medicine, Tohoku University \\ Graduate School of Medicine, Sendai, \\ Miyagi, Japan; ${ }^{4}$ Department of \\ Respiratory Medicine, National Hospital \\ Organization Asahikawa Medical Center, \\ Asahikawa, Hokkaido, Japan; \\ ${ }^{5}$ Department of Respiratory Medicine, \\ National Hospital Organization Fukuoka \\ Hospital, Fukuoka, Japan
}

Purpose: The improvement of physical activity in patients with COPD is an important issue. However, no standard for the recommended number of steps for patients with COPD has been determined. We conducted a retrospective observational study to create a simple standard equation for the daily step count, which makes it easier to determine whether each subject is attaining his/her predicted value or not.

Patients and methods: Stable outpatients diagnosed with COPD whose physical activities had been measured using a triaxial accelerometer for more than 2 weeks were recruited from 5 institutes in Japan. Factors associated with the step count were detected by multivariate regression analysis. After the data were transformed to a normalized distribution, a multivariate linear regression equation was created using stepwise regression.

Results: One hundred sixty-two patients aged 72.3 (7.2) years and of FEV1 \%pred 59.2 (22.8) \% were recruited. Among the parameters, age, mMRC dyspnea scale and inspiratory capacity (IC) were detected by the stepwise method. The created standard equation was "Step count $=(-0.079 \times[\text { age }]-1.595 \times[\mathrm{mMRC}]+2.078 \times[\mathrm{IC}]+18.149)^{3}$ ". The correlations between the calculated values and the measured values were observed, and fixed, and proportional biases between them were also observed. When patients with $<6500$ steps/day were selected, no systematic bias between them could be detected.

Conclusion: A simple standard equation for Japanese patients with COPD was created using age, mMRC and IC, and could provide an individual-predicted value, especially for patients with $<6500$ steps/day.

Keywords: COPD, physical activity, behavior modification, goal setting, accelerometer

\section{Plain language summary}

A simple standard equation for step count in Japanese patients with COPD was created using age, mMRC and IC. This could become helpful to determine whether each subject is attaining his/her predicted value or not.

\section{Introduction}

Correspondence: Yoshiaki Minakata Department of Respiratory Medicine, National Hospital Organization Wakayama Hospital, II 38 Wada Mihama-cho, Hidaka-gun, Wakayama 644-0044, Japan

Tel +8I 738223256

Fax +81738222126

Email minakata.yoshiaki.qy@mail.hosp.go.jp
Physical activity (PA) in patients with COPD is decreased compared to that in healthy subjects. ${ }^{1,2}$ Reduced PA is associated with mortality ${ }^{3-5}$ and is the greatest risk factor of COPD mortality. ${ }^{4}$ Therefore, the importance of maintenance and improvement of the PA in patients with COPD has been receiving increased attention.

Though the effects of several interventions such as bronchodilators, ${ }^{6-10}$ rehabilitation, ${ }^{11-13}$ or counseling ${ }^{14}$ on the PA in patients with COPD are still 
controversial, larger improvement in PA tended to be observed with counseling than with bronchodilators or rehabilitation. $^{15}$ It has been suggested that counseling should include a goal-setting, an improved motivation, and a feedback. ${ }^{16}$

The American College of Sports Medicine and the American Heart Association have recommended moderate-intensity aerobic PA for a minimum of 30 mins on 5 days each week for the general population aged 65 years or over. ${ }^{17}$ However, the recommended step count for patients with COPD has not been determined. As PA is restricted due to decreased pulmonary function and other factors in patients with COPD, ${ }^{18}$ a goal equivalent to that for healthy subjects might be excessive. The recommended value should be decided based on the predicted value of steps in each COPD patient. Therefore, it is necessary to determine the predicted value of steps in each patient with COPD, which makes it easier to determine whether each subject is attaining his/her predicted value or not.

The aim of this study was to produce a simple standard equation for the daily step count using some factors that influence PA in Japanese patients with COPD.

\section{Subjects and methods Subjects}

All stable outpatients with COPD whose physical activities had been measured using a triaxial accelerometer for more than 2 weeks and whose post-bronchodilator spirometry and mMRC dyspnea scale were evaluated within the past 3 months based on PA assessment with written informed consent from October 2009 to December 2017 at National Hospital Organization (NHO) Fukuoka Hospital, Wakayama Medical University, Tohoku University, NHO Wakayama Hospital, or NHO Asahikawa Medical Center were retrospectively recruited.

COPD was diagnosed as a post-bronchodilator FEV1/ FVC $<0.7$. Patients were excluded if they had clinically evident bronchial asthma or bronchiectasis, an exacerbation in the past 4 weeks, factors that obviously influenced their PA such as trauma and lower limb paralysis, decreased cognitive function, received rehabilitation program, or been judged inappropriate to register by a physician.

\section{Study protocol}

The step count was measured using an Actimarker (AM; Panasonic, Osaka Japan) at Wakayama Medical University, Tohoku University, NHO Wakayama Hospital, and NHO
Asahikawa Medical Center, and was measured using an active style Pro HJA-350 (HJA-350; OMRON, Kyoto Japan) at NHO Fukuoka Hospital. Participants were required to wear the accelerometer for $24 \mathrm{hrs}$ excluding bathing time. The reproducibility between the step count measured by AM and those by active style Pro HJA-750C (HJA-750C; OMRON), which was programed with the same algorism as that for the HJA-350, was evaluated by wearing both devices at the same time for 1 week (Table S1, Figure S1). Both AM and HJA-750C were already validated for evaluating $\mathrm{PA}$ in patients with COPD. ${ }^{19,20}$

From among the analyzing parameters including anthropometric data, symptoms, and the values of the respiratory function test, the factors associated with the step count were extracted. Then, a standard equation for the step count was created. This study has been approved by the ethics committee of Wakayama Medical University (approval number 2131, October 4, 2017) and also the ethics committee of each cooperative facility and has been registered with the University Hospital Medical Information Network (UMIN000029518, October 12, 2017). The contents of this study and the opportunity to reject the agreement were explained on the website of Third Department of Internal Medicine, Wakayama Medical University.

\section{Evaluation of measured step count}

From among the measured 2 weeks, the first and last days, holidays and rainy days, and days with monitoring for $<8$ hrs were excluded, and the mean value of the data extracted from the remaining at least 3 days was employed as the representative step count of each patient. The reason for these exclusions was that data of the whole day were not obtained on the first and last days, and that the PA on rainy days decreases ${ }^{19,20}$ and that PA on holidays tended to decrease. $^{21,22}$ More than 8 or $10 \mathrm{hrs}$ of monitoring time were recommended in previous reports. ${ }^{23}$ The reproducibility of PA measured by AM or HJA-750C with at least 3-day monitoring has been confirmed. ${ }^{19,20}$ The data of subjects who had $<3$ valid days of measuring were excluded.

\section{Analyzing parameters}

Age, gender, body mass index (BMI), FEV1\% of predicted (FEV1\%pred), FVC \% of predicted (FVC \%pred), inspiratory capacity (IC) and mMRC dyspnea scale were employed for evaluating associations with the step count. 


\section{Respiratory function test}

Spirometry was performed in the post-bronchodilator condition. CHESTAC-8800, 8900 or 9800 (CHEST, Tokyo, Japan) which measure volume signal were used at NHO Fukuoka Hospital, Wakayama Medical University, Tohoku University and NHO Wakayama Hospital, and DISCOM21 FXII (CHEST) which measures flow signal was used at NHO Asahikawa Medical Center.

\section{Statistical analysis}

The statistical analysis was performed using GraphPad Prism 5 (GraphPad Software, San Diego, CA, USA) and IBM SPSS Statistics (IBM Japan, Tokyo, Japan). D’Agostino-Pearson test was used for the evaluation of a normal distribution. Univariate regression analysis and multivariate regression analysis were used to evaluate the correlation between the step count and analyzed parameters. The Box-Cox transformation was used for normalizing the distribution of the step count values. Stepwise regression was used for creating the multivariate linear regression equation for the step count values. Linear regression analysis and Bland-Altman plots were used for comparisons between the measured and calculated step counts. The level of statistical significance was considered as $P<0.05$.
Based on a previous report about the correlation coefficient between the duration of PA and mMRC $(\mathrm{r}=0.313){ }^{2}$ when we set alpha as 0.05 (two-sided), beta as 0.10 and the expected dropout rate as $20 \%$, the required sample size was 142 , respectively. Therefore, we decided to require more than 142 subjects for this study.

\section{Results}

One hundred sixty-two COPD patients aged 72.3 (7.2) years and with FEV1\%pred 59.2 (22.8) \% (59 at NHO Fukuoka Hospital, 46 at Wakayama Medical University, 35 at Tohoku University, 12 at NHO Wakayama Hospital, 10 at NHO Asahikawa Medical Center) were recruited (Table 1). The reproducibility between AM and HJA-750C was evaluated for 12 stable outpatients with COPD aged 76.6 (6.9) years and with FEV1\%pred 57.6 (18.6) \% (Table S1). As the data from 3 days in each patient were monitored, in total 36 sets of data were evaluated. The correlation between the step counts measured by AM and those measured by HJA-750C was statistically significant $(\mathrm{r}=0.990, \quad P<0.0001)$ by linear regression analysis (Figure S1A). Furthermore, there was no systematic bias and the reproducibility was confirmed by Bland-Altman plot (mean of difference $95 \%$ CI: -30.23 to 131.43 , limit

Table I Characteristics of patients

\begin{tabular}{|c|c|c|c|c|c|c|}
\hline & Total & $\begin{array}{l}\text { NHO } \\
\text { Fukuoka }\end{array}$ & $\begin{array}{l}\text { Wakayama } \\
\text { MU }\end{array}$ & Tohoku U & $\begin{array}{l}\text { NHO } \\
\text { Wakayama }\end{array}$ & $\begin{array}{l}\text { NHO } \\
\text { Asahikawa }\end{array}$ \\
\hline Age (years) & $72.3(7.2)$ & $73.6(7.0)$ & $71.6(7.1)$ & $69.0(7.2)$ & $76.6(6.9)$ & $74.8(5.4)$ \\
\hline Gender (M/F), $n$ & $150 / 12$ & $52 / 7$ & $44 / 2$ & $34 / 1$ & $\mathrm{II} / \mathrm{I}$ & $9 / 1$ \\
\hline \multicolumn{7}{|l|}{ Smoking history } \\
\hline Pack-years & $59.0(34.0)$ & $46.5(24.9)$ & $66.0(35.6)$ & $62.0(33.2)$ & $88.1(53.1)$ & $55.9(18.6)$ \\
\hline Curr/ex/non, $\mathrm{n}$ & $25 / 134 / 3$ & $9 / 48 / 2$ & $10 / 36 / 0$ & $0 / 35 / 0$ & $4 / 7 / 1$ & $2 / 8 / 0$ \\
\hline BMI & $21.5(3.4)$ & $22.1(3.9)$ & $21.2(3.5)$ & $21.4(2.6)$ & $19.9(2.5)$ & $21.7(2.7)$ \\
\hline GOLD stage $(\mathrm{I} / \mathrm{II} / \mathrm{III} / \mathrm{IV}), \mathrm{n}$ & $29 / 72 / 44 / 17$ & $14 / 23 / 13 / 9$ & $6 / 23 / 11 / 6$ & $6 / 16 / 11 / 2$ & $1 / 5 / 6 / 0$ & $2 / 5 / 3 / 0$ \\
\hline mMRC scale $(0 / 1 / 2 / 3 / 4), n$ & $35 / 58 / 34 / 25 / 10$ & $10 / 23 / 13 / 7 / 6$ & $|3 /| 7 / 8 / 7 / \mid$ & $10 / 12 / 9 / 3 / 1$ & $1 / 4 / 1 / 6 / 0$ & $1 / 2 / 3 / 2 / 2$ \\
\hline \multicolumn{7}{|l|}{ Pulmonary function } \\
\hline IC (L) & $2.03(0.50)$ & $2.01(0.60)$ & $2.03(0.44)$ & $2.14(0.46)$ & $1.90(0.40)$ & $1.89(0.35)$ \\
\hline FVC (L) & $3.13(0.73)$ & $2.99(0.78)$ & $3.34(0.59)$ & $3.20(0.86)$ & $2.78(0.60)$ & $3.11(0.50)$ \\
\hline FVC \% of predicted (\%) & $94.8(19.1)$ & $95.4(21.7)$ & $97.5(12.8)$ & $90.9(21.5)$ & $86.1(20.4)$ & $103.4(9.59)$ \\
\hline FEVI (L) & $1.54(0.63)$ & $\mathrm{I} .53(0.7 \mathrm{I})$ & $1.56(0.57)$ & $1.69(0.63)$ & $\mathrm{I} .43(0.37)$ & $1.20(0.49)$ \\
\hline FEVI/FVC (\%) & $48.5(13.5)$ & $49.5(14.6)$ & $46.0(13.8)$ & $51.8(10.7)$ & $51.7(9.15)$ & $38.5(13.3)$ \\
\hline FEVI\% of predicted (\%) & $59.2(22.8)$ & $61.7(27.6)$ & $56.6(19.5)$ & $58.9(20.1)$ & $57.6(18.6)$ & $60.1(21.8)$ \\
\hline
\end{tabular}

Note: Data are presented as mean (SD).

Abbreviations: M, male; F, female; curr, current smoker; ex, ex-smoker; non, non-smoker; BMI, Body Mass Index; IC, inspiratory capacity; NHO Fukuoka, NHO Fukuoka Hospital; Wakayama MU, Wakayama Medical University; Tohoku U, Tohoku University; NHO Wakayama, NHO Wakayama Hospital; NHO Asahikawa, NHO Asahikawa Medical Center; NHO, National Hospital Organization. 
Table 2 Univariate and multivariate regression analysis of step count

\begin{tabular}{|l|l|l|l|l|}
\hline \multirow{2}{*}{ Variables } & \multicolumn{2}{|l|}{ Univariate } & \multicolumn{2}{l|}{ Multivariate } \\
\cline { 2 - 5 } & $\mathbf{r}$ & $\boldsymbol{P}$-value & $\boldsymbol{\beta}$ & $P$-value \\
\hline Age & -0.280 & $<0.00 \mathrm{I}$ & -0.209 & 0.008 \\
Gender & 0.085 & 0.280 & 0.023 & 0.769 \\
BMI & 0.163 & 0.038 & 0.034 & 0.647 \\
mMRC scale & -0.422 & $<0.00 \mathrm{I}$ & $-0.27 \mathrm{I}$ & $0.00 \mathrm{I}$ \\
IC (L) & 0.342 & $<0.00 \mathrm{I}$ & $0.1 \mathrm{II}$ & 0.257 \\
FVC \% predicted (\%) & 0.262 & $<0.00 \mathrm{I}$ & 0.003 & 0.974 \\
FEVI\% predicted (\%) & 0.328 & $<0.00 \mathrm{I}$ & 0.134 & 0.248 \\
\hline
\end{tabular}

Abbreviations: $r$, correlation coefficient; $\beta$, standardized partial regression coefficient; BMI, body mass index; IC, inspiratory capacity.

of agreement: -417.6 to 518.9) (Figure S1B). The step count was significantly correlated with age, BMI, mMRC scale, IC, FVC \%pred and FEV1\%pred with univariate regression analysis (Table 2, Figure 1), and correlated with age and $\mathrm{mMRC}$ with multivariate regression analysis (Table 2). As the measured step counts were not normally distributed (Figure 2), data were transformed to a normal distribution with Box-Cox transformation $(\lambda=0.33)$ in order to create the multiple linear regression equation. When the stepwise method was employed, age, mMRC and IC were extracted from among the analyzed parameters, a linear regression equation of the transformed step count was created with those 3 parameters as independent variables. The equation for the untransformed step count was reconstituted from the equation for the transformed step count:

$$
\begin{aligned}
\text { Step count } & =(-0.079 \times[\text { age }]-1.595 \times[\mathrm{mMRC}] \\
& +2.078 \times[\mathrm{IC}]+18.149)^{3}
\end{aligned}
$$

Correlation between the measured data and calculated data was observed by linear regression analysis $(\mathrm{r}=0.470$, $P<0.0001$ ), but there was a fixed bias (mean of difference 95\% CI: $0.1163-1816.2$, limit of agreement: -4909 to 6726 ) and a proportional bias between the two sets of data (Figure 3 ). When only patients with $<6500$ of measured step count were selected, 121 patients among 162 were extracted. Correlation between the two sets of data was observed $(r=0.435$, $P<0.0001$ ), and there was no fixed bias (mean of difference 95\% CI: -773.32 to 0.06537 , limit of agreement: -3908.7 to 3135.5) and no proportional bias between them as determined by the Bland-Altman plot (Figure 4).

\section{Discussion}

From retrospective data, we demonstrated that the step count was associated with age and mMRC using multivariate linear regression analysis. By using age, mMRC and IC, which were extracted by a stepwise method as independent variables, we could create a standard equation for the step count in Japanese patients with COPD.

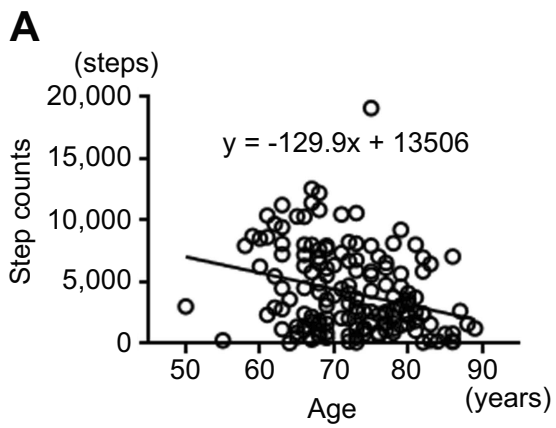

B
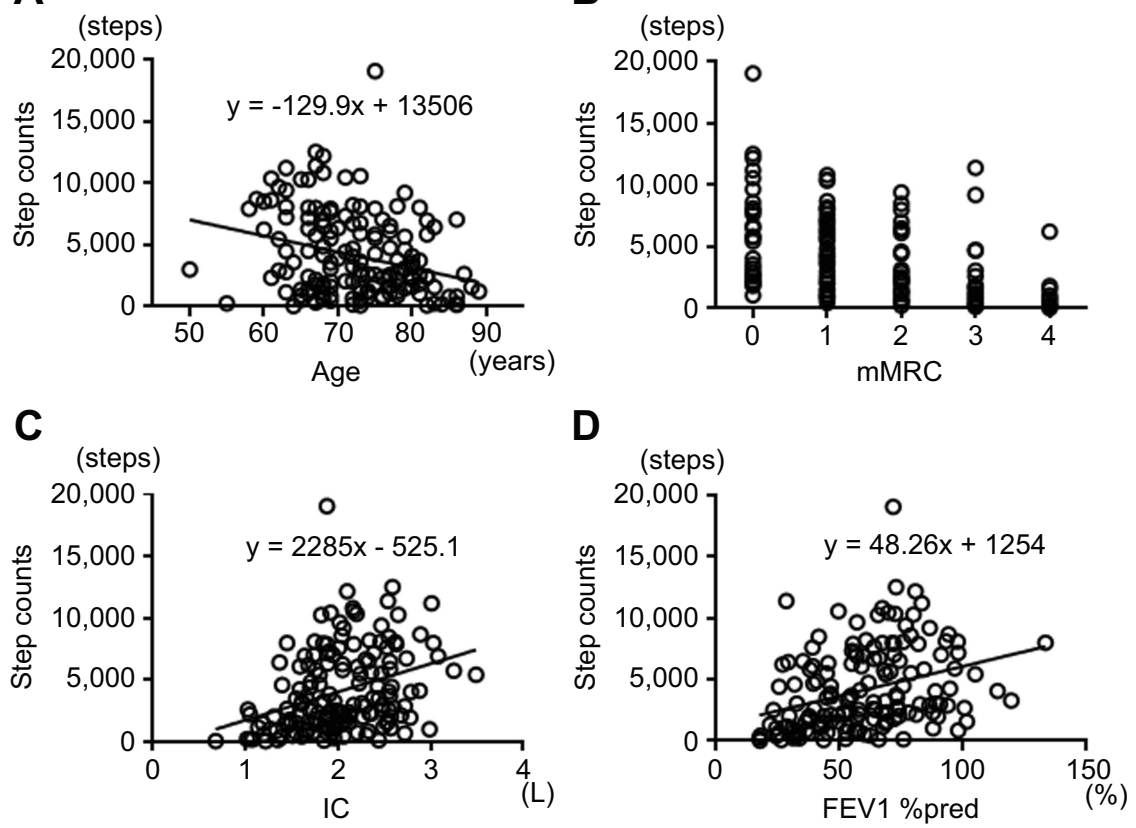

Figure I Correlations between step count and associated variables: (A) age, (B) mMRC, (C) IC, and (D) FEVI\%pred. Abbreviations: mMRC, mMRC dyspnea scale; IC, inspiratory capacity; FEVI\%pred, FEV \% of predicted. 


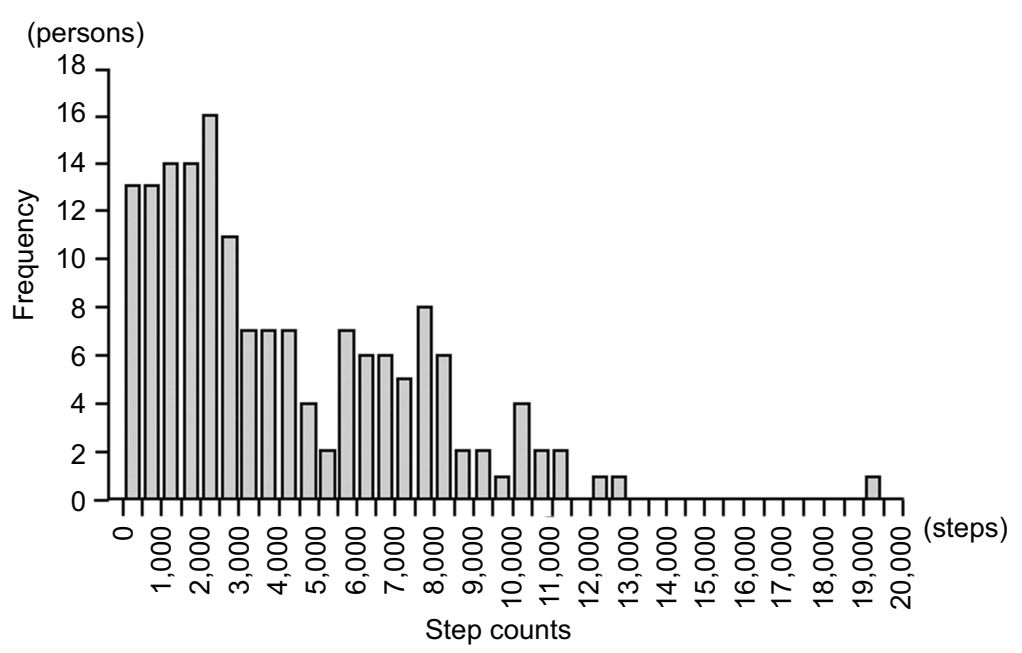

Figure 2 Histogram of measured step count.

With a univariate linear regression analysis, the step count was associated with age, BMI, mMRC, IC, FVC and FEV1. PA in patients with COPD has been shown to be associated with age ${ }^{24}$ and dyspnea. ${ }^{22,24-26} \mathrm{PA}$ has also been shown to be associated with $\mathrm{FEV} 1^{1,22,25,27}$ and FVC, ${ }^{1,27}$ but these associations were weak-to-moderate. We have previously reported that PA was associated with FVC, FEV1, mMRC and age, ${ }^{2}$ and that $\mathrm{mMRC} \geq 2$ was the cut off value for detecting patients with low PA. ${ }^{28}$ All of these reports are compatible with the current results.

Concerning pulmonary function, IC but not FEV1 was detected by stepwise method as a factor influencing the step count in the current study. Sounders et al. ${ }^{29}$ reported meta-analyses for factors associated with steps/day in patients with COPD. They found that the only variable associated with steps/day after adjustment for covariates by multivariate meta-regression was FEV1\%pred, which

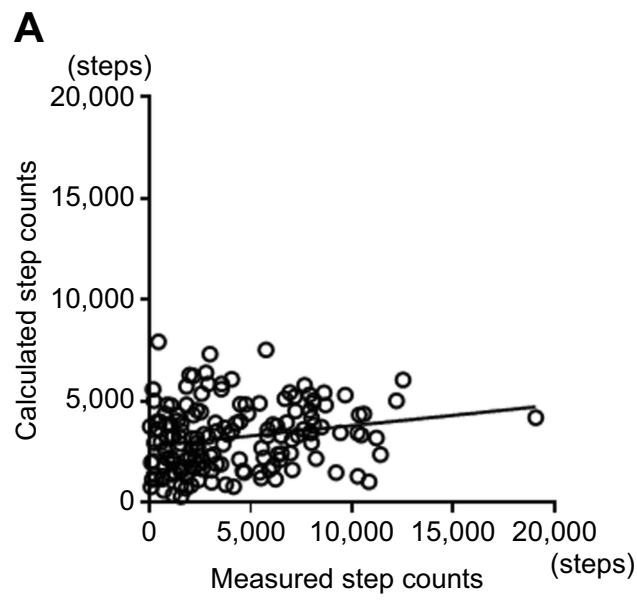

was not compatible with our results. In their report, however, among the values of pulmonary function, only FEV1\%pred was employed for analysis and IC was not evaluated. Lahaije et al. ${ }^{30}$ reported that both resting IC/ total lung capacity and dynamic hyperinflation uniquely contributed to PA in patients with COPD but FEV1\%pred did not, which supports our results. IC might influence the step count more than FEV1 in patients with COPD.

The average step count of 46 countries obtained from the data of Apple iPhone smartphone users of the Azumio Argus application, was 4961 steps per day. Among the 46 countries, Japan showed a relatively high step count $(5800-5900$ steps). ${ }^{31}$ Ministry of Health, Labor and Welfare of Japan reported that the average step count of general population aged 20 to 64 was 7636 in males and 6657 in females, and that of aged 65 or over was 5597 in males and 4726 in females. ${ }^{32}$ The recommended step count for subjects aged

B

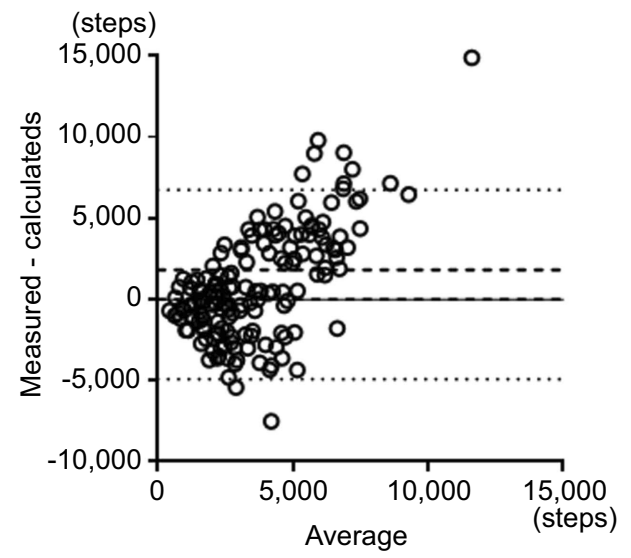

Figure 3 Correlation between measured and calculated step count: $(\mathbf{A})$ scatter plot, $r=0.470, P<0.000 \mathrm{I}$ and $(\mathbf{B})$ Bland-Altman plot. There were fixed and proportional biases (mean of difference $95 \% \mathrm{Cl}$ : $0.1163-1816.2$, limit of agreement: -4909 to 6726 ). Broken lines indicate mean difference $95 \% \mathrm{Cl}$ and dotted lines indicate limit of agreement. 

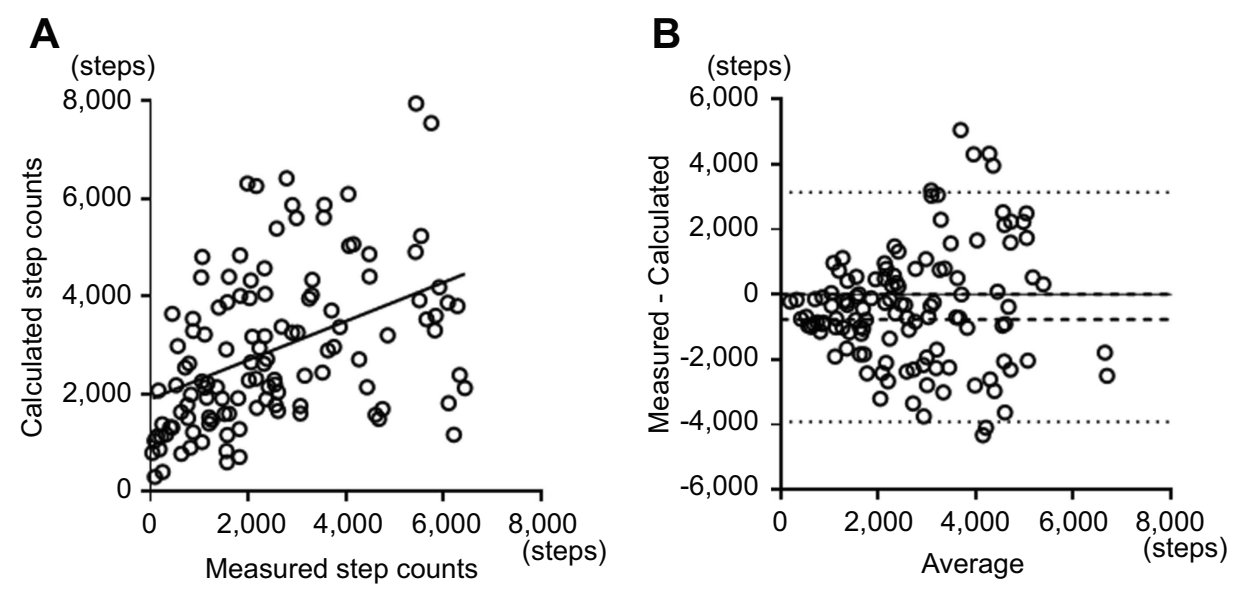

Figure 4 Correlation between measured and calculated step counts in patients with $<6500$ steps: (A) scatter plot, $r=0.435, P<0.000 \mathrm{I}$ and $(\mathbf{B})$ Bland-Altman plot. There was no systematic bias. (mean of difference $95 \% \mathrm{Cl}$ : -773.32 to 0.06537 , limit of agreement: -3908.7 to 3135.5 ). Broken lines indicate mean difference $95 \% \mathrm{Cl}$ and dotted lines indicate limit of agreement.

20 to 64 was 9000 in males and 8500 in females, and for aged 65 or over was 7000 in males and 6000 in females. ${ }^{33}$ However, as the exercise capacity is obviously low in COPD compared to healthy subjects, such a large number of steps could overburden patients with COPD. The optimalrecommended step count for patients with COPD should be determined based on the predicted value of steps calculated together with associated factors. This newly developed simple standard equation could provide a predicted step count for each patient with COPD.

The measured number of steps for COPD patients varied among the reports, and meta-analysis of 38 papers showed that the pooled mean estimate of steps in COPD was 4579.28. Only one Japanese report was included in this meta-analysis, and the average step count was $6241.3 .^{34}$ The step count of Japanese patients with COPD might be relatively higher compared to other countries. Furthermore, Japanese patients with COPD were reported to be relatively older, ${ }^{35}$ milder stage, ${ }^{36-38}$ and have fewer exacerbations ${ }^{36,39}$ than those in other countries. As PA is influenced by several factors including regional customs, economic condition and environment, the recommended step count might ideally be set separately in each country.

In our study, there were fixed and proportional biases between the measured and calculated step counts. The step count could be low in the most of patients but might be relatively high and sometimes very high in some patients with COPD. Actually, 41 patients (25.3\%) walked more than 6500 steps, which is the mean value of recommended steps for both genders aged 65 or over. ${ }^{33}$ Especially, one woman who was a hard-working farmer aged 75 years, with 71.7\% of FEV1\%pred and mMRC 0, walked 19060 steps. The PA in such patients is sufficient and further encouragement to improve their PA is not necessary. When only patients with step counts of $<6500$ were selected, neither fixed nor proportional biases between the measured and calculated step counts could be detected in the Bland-Altman plot. The presence of the few patients with high step counts might have caused the biases; therefore, our newly developed equation might be useful for patients with step counts of $<6500$.

There are two types of sensors which detect the step count, the pendulum and accelerometer, and the worn parts differ among devices. As both AM and HJA-350 are accelerometers worn on the waist, differences in the data from the two types of devices would likely be small. In order to confirm the reproducibility of both devices, the data from AM and those from HJA-750C, which was programed with same algorism as that for the HJA-350, were compared. Data from both devices were significantly correlated by regression analysis and there was no systematic bias in the Bland-Altman plots (Figure S1), which indicated the obtained data were reproducible and could be evaluated together.

The step count is a parameter of PA, but it does not reflect the intensity of activity. In patients with COPD with FEV1\%pred $<50 \%$, the risk of hospitalization decreases as step count increases when the patients' mean intensities of PA are low $(<2.7$ metabolic equivalents). On the other hand, the risk of hospitalization increases as the step count increases when their mean intensities are high ( $\geq 2.7$ metabolic equivalents). ${ }^{40}$ This report suggested that 
an increased step count with light intensity should be recommended for patients with severe or very severe COPD. As not only the step count but also the intensity of activity could be important, the mean intensity of activity should be taken into account when the calculated step count is employed for goal setting.

There are several limitations which should be addressed. First, the number of recruited female patients was small (only 12 patients). As gender was not associated with the step count when analyzed as a dependent variable, both genders were included in the same equation in the current study. A larger number of patients might require two equations performed separately for each gender. Second, the factors associated with the step count were evaluated with only age, gender, $\mathrm{BMI}, \mathrm{mMRC}$ and the data of spirometry as dependent variables, but other factors were not evaluated. Many other factors including exercise capacity, muscle strength, diffusing capacity, comorbidities, mental status, occupations, and environmental factors are presumed to influence the step count. Therefore, although the obtained equation might not be very precise, but somewhat rough, this could provide a simple standard step count for patients with COPD using easily obtained variables in the clinical setting. Further study is required to create a more precise equation of the step count using other factors. Third, the step count was not evaluated by a single accelerometer but two types of accelerometers, AM and HJA-350C. Though the reproducibility of the 2 devices was confirmed, ideally, it is better to measure with a single device to completely exclude a measuring bias. Fourth, the measured step count showed a non-normal distribution. The process of normalization with the Box-Cox transformation was required for employing the multiple regression equation, which made the final equation somehow complex. Many patients demonstrated low step counts but some patients demonstrated high step counts, probably according to their individual circumstances. This tendency may have caused a non-normal distribution of the step counts. Fifth, we excluded the data of holidays. As the inclusion or exclusion of holidays is still controversial, the necessity of the data of holidays might be evaluated in another study. Sixth, this was a retrospective study and the data were obtained from several institutes and with different spirometers. These conditions might have induced biases in the step count. A further prospective study will be needed. Seventh, since this developed equation has not been validated in other groups of COPD subjects, it should be confirmed in a future study.

In conclusion, a simple standard equation for the step count in Japanese patients with COPD was created using age, mMRC and IC. This equation could provide the predicted value of steps in individual patients, especially for patients with $<6500$ steps/day.

\section{Ethics approval and informed consent}

This study has been approved by the ethics committee of Wakayama Medical University (approval number 2131, October 4, 2017) and also the ethics committee of each cooperative facility and has been registered with the University Hospital Medical Information Network (UMIN000029518, October 12, 2017). Written informed consent had been obtained from each patient at each institute. The contents of this study and the opportunity to reject the agreement were explained on the website of Third Department of Internal Medicine, Wakayama Medical University.

\section{Data sharing statement}

The clinical study data used to support the findings of this study are available from the corresponding author upon request.

\section{Abbreviations}

NHO, National Hospital Organization; AM, Actimarker; HJA-350, active style pro HJA-350; HJA-750C, active style pro HJA-750C; PA, physical activity; BMI, body mass index; IC, inspiratory capacity

\section{Acknowledgments}

The authors thank Mr Brent Bell for proof reading the manuscript. This study was commissioned and supported by the Environmental Restoration and Conservation Agency of Japan.

\section{Author contributions}

All authors contributed to data analysis, drafting and revising the article, gave final approval of the version to be published, and agree to be accountable for all aspects of the work.

\section{Disclosure}

YM received lecturer fee from Nippon Boehringer Ingelheim. The authors report no other conflicts of interest in this work. 


\section{References}

1. Pitta F, Troosters T, Spruit MA, Probst VS, Decramer M, Gosselink R. Characteristics of physical activities in daily life in chronic obstructive pulmonary disease. Am J Respir Crit Care Med. 2005;171(9):972-977. doi:10.1164/rccm.200407-855OC

2. Minakata Y, Sugino A, Kanda M, et al. Reduced level of physical activity in Japanese patients with chronic obstructive pulmonary disease. Respir Investig. 2014;52(1):41-48. doi:10.1016/j.resinv.2013.06.002

3. Garcia-Aymerich J, Lange P, Benet M, Schnohr P, Anto JM. Regular physical activity reduces hospital admission and mortality in chronic obstructive pulmonary disease: a population based cohort study. Thorax. 2006;61(9):772-778. doi:10.1136/thx.2006.060145

4. Waschki B, Kirsten A, Holz O, et al. Physical activity is the strongest predictor of all-cause mortality in patients with COPD: a prospective cohort study. Chest. 2011;140(2):331-342. doi:10.1378/chest.10-2521

5. Garcia-Rio F, Rojo B, Casitas R, et al. Prognostic value of the objective measurement of daily physical activity in patients with COPD. Chest. 2012;142(2):338-346. doi:10.1378/chest.11-2014

6. Watz H, Krippner F, Kirsten A, Magnussen H, Vogelmeier C. Indacaterol improves lung hyperinflation and physical activity in patients with moderate chronic obstructive pulmonary disease-a randomized, multicenter, double-blind, placebo-controlled study. BMC Pulm Med. 2014;14:158. doi:10.1186/1471-2466-14-158

7. Beeh KM, Watz H, Puente-Maestu L, et al. Aclidinium improves exercise endurance, dyspnea, lung hyperinflation, and physical activity in patients with COPD: a randomized, placebo-controlled, crossover trial. BMC Pulm Med. 2014;14(1):209. doi:10.1186/1471-2466-14-209

8. Minakata Y, Morishita Y, Ichikawa T, et al. Effects of pharmacologic treatment based on airflow limitation and breathlessness on daily physical activity in patients with chronic obstructive pulmonary disease. Int $J$ Chron Obstruct Pulmon Dis. 2015;10:1275-1282. doi: $10.2147 /$ COPD.S84134

9. O'Donnell DE, Casaburi R, Vincken W, et al. Effect of indacaterol on exercise endurance and lung hyperinflation in COPD. Respir Med. 2011;105(7):1030-1036. doi:10.1016/j.rmed.2011.03.014

10. Troosters T, Sciurba FC, Decramer M, et al. Tiotropium in patients with moderate COPD naive to maintenance therapy: a randomised placebo-controlled trial. NPJ Prim Care Respir Med. 2014;24:14003. doi:10.1038/npjpcrm.2014.3

11. Griffiths TL, Burr ML, Campbell IA, et al. Results at 1 year of outpatient multidisciplinary pulmonary rehabilitation: a randomised controlled trial. Lancet. 2000;355(9201):362-368. doi:10.1016/s0140-6736(99)07042-7

12. Pitta F, Troosters T, Probst VS, Langer D, Decramer M, Gosselink R. Are patients with COPD more active after pulmonary rehabilitation? Chest. 2008;134(2):273-280. doi:10.1378/chest.07-2655

13. Mador MJ, Patel AN, Nadler J. Effects of pulmonary rehabilitation on activity levels in patients with chronic obstructive pulmonary disease. J Cardiopulm Rehabil Prev. 2011;31(1):52-59. doi:10. 1097/HCR.0b013e3181ebf2ef

14. Mendoza L, Horta P, Espinoza J, et al. Pedometers to enhance physical activity in COPD: a randomised controlled trial. Eur Respir J. 2015;45(2):347-354. doi:10.1183/09031936.00084514

15. Shioya T, Sato $S$, Iwakura M, et al. Improvement of physical activity in chronic obstructive pulmonary disease by pulmonary rehabilitation and pharmacological treatment. Respir Investig. 2018;56(4):292-306. doi:10.1016/j.resinv.2018.05.002

16. Altenburg WA, Ten Hacken NH, Bossenbroek L, Kerstjens HA, de Greef $\mathrm{MH}$, Wempe JB. Short- and long-term effects of a physical activity counselling programme in COPD: a randomized controlled trial. Respir Med. 2015;109(1):112-121. doi:10.1016/j.rmed.2014.10.020

17. Nelson ME, Rejeski WJ, Blair SN, et al. Physical activity and public health in older adults: recommendation from the American college of sports medicine and the American heart association. Circulation. 2007;116(9):1094-1105. doi:10.1161/CIRCULATIONAHA.107.185650
18. Watz H, Pitta F, Rochester CL, et al. An official European Respiratory Society statement on physical activity in COPD. Eur Respir J. 2014;44(6):1521-1537. doi:10.1183/09031936.00046814

19. Sugino A, Minakata Y, Kanda M, et al. Validation of a compact motion sensor for the measurement of physical activity in patients with chronic obstructive pulmonary disease. Respiration. 2012;83 (4):300-307. doi:10.1159/000330046

20. Miyamoto S, Minakata Y, Azuma Y, et al. Verification of a motion sensor for evaluating physical activity in COPD patients. Can Respir J. 2018;2018:8343705. doi:10.1155/2018/8343705

21. Rabinovich RA, Louvaris Z, Raste Y, et al. Validity of physical activity monitors during daily life in patients with COPD. Eur Respir J. 2013;42(5):1205-1215. doi:10.1183/09031936.00134312

22. Watz H, Waschki B, Meyer T, Magnussen H. Physical activity in patients with COPD. Eur Respir J. 2009;33(2):262-272. doi:10.1183/ 09031936.00024608

23. Byrom B, Rowe DA. Measuring free-living physical activity in COPD patients: deriving methodology standards for clinical trials through a review of research studies. Contemp Clin Trials. 2016;47:172-184. doi:10.1016/j.cct.2016.01.006

24. Hernandes NA, Teixeira Dde C, Probst VS, Brunetto AF, Ramos EM, Pitta F. Profile of the level of physical activity in the daily lives of patients with COPD in Brazil. J Bras Pneumol. 2009;35(10):949956. doi:10.1590/s1806-37132009001000002

25. Steele BG, Holt L, Belza B, Ferris S, Lakshminaryan S, Buchner DM. Quantitating physical activity in COPD using a triaxial accelerometer. Chest. 2000;117(5):1359-1367. doi:10.1378/chest.117.5.1359

26. Waschki B, Spruit MA, Watz H, et al. Physical activity monitoring in COPD: compliance and associations with clinical characteristics in a multicenter study. Respir Med. 2012;106(4):522-530. doi:10.1016/j. rmed.2011.10.022

27. Walker PP, Burnett A, Flavahan PW, Calverley PM. Lower limb activity and its determinants in COPD. Thorax. 2008;63(8):683689. doi:10.1136/thx.2007.087130

28. Hayata A, Minakata Y, Matsunaga K, Nakanishi M, Yamamoto N. Differences in physical activity according to $\mathrm{mMRC}$ grade in patients with COPD. Int J Chron Obstruct Pulmon Dis. 2016;11:2203-2208. doi:10.2147/COPD.S109694

29. Saunders T, Campbell N, Jason T, et al. Objectively measured steps/ day in patients with chronic obstructive pulmonary disease: a systematic review and meta-analysis. J Phys Act Health. 2016;13 (11):1275-1283. doi:10.1123/jpah.2016-0087

30. Lahaije AJ, van Helvoort HA, Dekhuijzen PN, Vercoulen JH, Heijdra YF. Resting and ADL-induced dynamic hyperinflation explain physical inactivity in COPD better than FEV1. Respir Med. 2013;107 (6):834-840. doi:10.1016/j.rmed.2013.02.017

31. Althoff T, Sosic R, Hicks JL, King AC, Delp SL, Leskovec J. Largescale physical activity data reveal worldwide activity inequality. Nature. 2017;547(7663):336-339. doi:10.1038/nature23018

32. National Institute of Health and Nutrition. The National Health and Nutrition Survey in Japan 2017. Tokyo, Japan, 2018 (in Japanese). Available from: https://www.mhlw.go.jp/content/000451758.pdf. Accessed January 7, 2019

33. National Institute of Health and Nutrition. Table 5, (2) Physical activity and exercise in List of Targets, Health Japan 21 (the second term), Tokyo, Japan. Available from: https://www.nibiohn.go.jp/eiken/kenkou nippon21/en/kenkounippon21/mokuhyou05.html. Accessed January 7, 2019.

34. Hataji O, Naito M, Ito K, Watanabe F, Gabazza EC, Taguchi O. Indacaterol improves daily physical activity in patients with chronic obstructive pulmonary disease. Int J Chron Obstruct Pulmon Dis. 2013;8:1-5. doi:10.2147/COPD.S38548

35. Portal Site of Official Statistics of Japan (S-Stat). Patient Survey 2017 (in Japanese), Tokyo, Japan, 2019. Available from: https:// www.e-stat.go.jp/dbview?sid=0003318584. Accessed January 7, 2019. 
36. Landis SH, Muellerova H, Mannino DM, et al. Continuing to confront COPD international patient survey: methods, COPD prevalence, and disease burden in 2012-2013. Int J Chron Obstruct Pulmon Dis. 2014;9:597-611. doi:10.2147/COPD.S61854

37. Fukuchi Y, Nishimura M, Ichinose M, et al. COPD in Japan: the nippon COPD epidemiology study. Respirology. 2004;9(4):458-465. doi:10.1111/j.1440-1843.2004.00637.x

38. Matsumoto K, Seki N, Fukuyama S, et al. Prevalence of asthma with airflow limitation, COPD, and COPD with variable airflow limitation in older subjects in a general Japanese population: the Hisayama study. Respir Investig. 2015;53(1):22-29. doi:10.1016/j.resinv.2014.08.002
39. Ishii $T$, Nishimura $M$, Akimoto A, James $M H$, Jones $P$ Understanding low COPD exacerbation rates in Japan: a review and comparison with other countries. Int J Chron Obstruct Pulmon Dis. 2018;13:3459-3471. doi:10.2147/COPD.S165187

40. Donaire-Gonzalez D, Gimeno-Santos E, Balcells E, et al. Benefits of physical activity on COPD hospitalisation depend on intensity. Eur Respir J. 2015;46(5):1281-1289. doi:10.1183/13993003.016 99-2014 


\section{Supplementary materials}

\section{Subjects and methods}

Stable outpatients with COPD were recreated at NHO Wakayama Hospital. COPD was diagnosed as a postbronchodilator FEV1/FVC $<0.7$. AM and HJA-750C were worn on the waist of patients at the same time for 1 week. The step counts measured by both devices were compared. Written informed consent was obtained from all patients. This study has been approved by the ethics committee of NHO Wakayama Hospital (approved number 8, March 20, 2017) and has been registered with the University Hospital Medical Information Network (UMIN000016363, January 28, 2015).

Table SI Characteristics of patients

\begin{tabular}{|c|c|}
\hline Age (years) & $76.6(6.9)$ \\
\hline Gender $(M / F), n$ & $\mathrm{II} / \mathrm{I}$ \\
\hline \multicolumn{2}{|l|}{ Smoking history } \\
\hline Pack-years & 96.1 (47.5) \\
\hline Curr/ex/non, $\mathrm{n}$ & $4 / 7 / 1$ \\
\hline BMI & $19.9(2.5)$ \\
\hline GOLD stage (I/II/III/IV), n & $1 / 5 / 6 / 0$ \\
\hline mMRC scale $(0 / 1 / 2 / 3 / 4), n$ & $1 / 4 / 1 / 6 / 0$ \\
\hline \multicolumn{2}{|l|}{ Pulmonary function } \\
\hline IC (L) & $\mathrm{I} .88(0.4 \mathrm{I})$ \\
\hline FVC (L) & $2.78(0.60)$ \\
\hline FVC \% of predicted (\%) & $86.1(20.4)$ \\
\hline FEVI (L) & $\mathrm{I} .43(0.37)$ \\
\hline FEVI/FVC (\%) & $51.7(9.2)$ \\
\hline FEVI\% of predicted (\%) & $57.6(18.6)$ \\
\hline
\end{tabular}

Note: Data are presented as mean (SD).

Abbreviations: M, male; F, female; curr, current smoker; ex, ex-smoker; non, non-smoker; BMI, Body Mass Index; GOLD, Global Initiative for Chronic Obstructive Lung Disease; IC, inspiratory capacity.

A

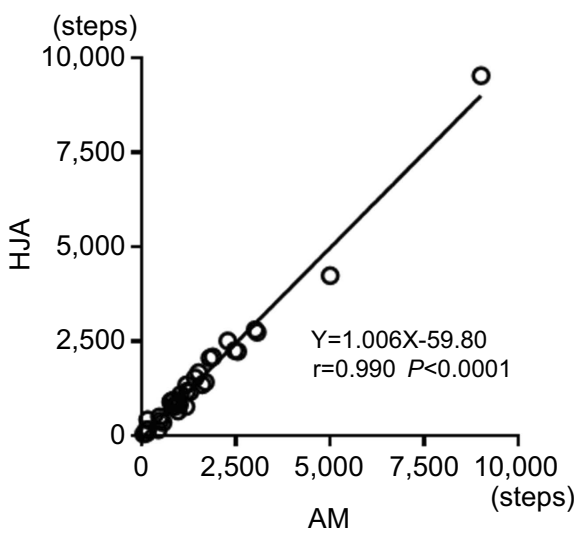

B

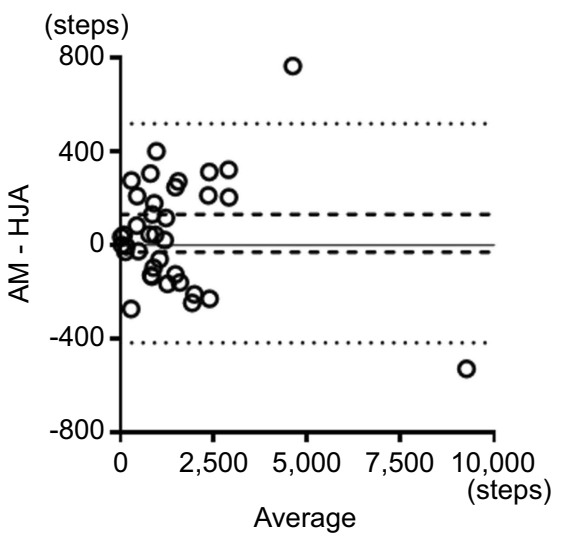

Figure SI Correlation between step counts by AM and HJA-750C. (A) scatter plot, $r=0.990 P<0.000$ I and (B) Bland-Altman plot. There was no systematic bias. (mean of difference $95 \% \mathrm{Cl}:-30.23$ to 131.43 , limit of agreement: -417.6 to 518.9 ). Broken lines indicate mean difference $95 \% \mathrm{Cl}$ and dotted lines indicate limit of agreement. Abbreviations: HJA-750C, Active Style Pro HJA-750C; AM, Actimarker. 


\section{Publish your work in this journal}

The International Journal of COPD is an international, peer-reviewed journal of therapeutics and pharmacology focusing on concise rapid reporting of clinical studies and reviews in COPD. Special focus is given to the pathophysiological processes underlying the disease, intervention programs, patient focused education, and self management

protocols. This journal is indexed on PubMed Central, MedLine and CAS. The manuscript management system is completely online and includes a very quick and fair peer-review system, which is all easy to use. Visit http://www.dovepress.com/testimonials.php to read real quotes from published authors.

Submit your manuscript here: https://www.dovepress.com/international-journal-of-chronic-obstructive-pulmonary-disease-journal 